\title{
ЦИФРОВЫЕ ТЕХНОЛОГИИ В МОЛОЧНОЙ ПРОМЫШЛЕННОСТИ
}

\author{
(c) 2020 Майоров Александр Альбертович \\ доктор технических наук, профессор, главный научный сотрудник, \\ зав. лабораторией технологий молочных продуктов \\ Федеральный Алтайский научный центр агробиотехнологий, Россия, Барнаул
}

(c) 2020 Сурай Наталья Михайловна

кандидат технических наук, доцент кафедры экономики и управления

Московский государственный университет технологий и управления (ПКУ), Россия, Москва

\section{(c) 2020 Носов Владимир Владимирович}

доктор экономических наук, профессор кафедры экономики и управления, зам. директора по научной работе

Московский государственный университет технологий и управления (ПКУ), Россия, Москва

\section{(C) 2020 Бобков Александр Николаевич}

доктор филологических наук, профессор кафедры экономики и управления

Московский государственный университет технологий и управления (ПКУ), Россия, Москва

\section{(c) 2020 Гарипова Лариса Владимировна}

кандидат экономических наук, доцент кафедры экономики и управления на предприятии Московский государственный университет технологий и управления (ПКУ), Россия, Мелеуз

Ключевые слова: цифровая экономика, сельское хозяйство, молочная промышленность, цифровые технологии, умная ферма, умное молочное стадо.

Пищевая индустрия - это сфера, от состояния которой зависит безопасность и качество продуктов питания. Один из трендов в современной пищевой промышленности - это комплексное проектирование и оснащение предприятий молочной индустрии. По прогнозам Организации Объединенных Наций к 2025 г. потребуется увеличить производство продуктов питания на 70\% [1]. Перед отечественной аграрной отраслью стоит задача повышения производительности труда и конкурентоспособности на основе применения новейших научных достижений и передового опыта.

Президент Российской Федерации В.В. Путин в послании к Федеральному Собранию РФ 1 марта 2018 г. призвал эффективно использовать накапливаемый в мире громадный технологический потенциал, который позволяет совершить технологический рывок и вывести экономику на новый уровень.

Цифровизация - это использование цифровых технологий для изменения бизнес-модели и предоставления новых возможностей для получения доходов и создания стоимости; это процесс перехода к цифровому бизнесу [2].

Распоряжением Правительства Российской
Федерации от 28 июля 2017 г. № 1632-р утверждена Госпрограмма «Цифровая экономика Российской Федерации», где указано: «...данные в цифровой форме являются ключевым фактором производства во всех сферах социальноэкономической деятельности, что повышает конкурентоспособность страны, качество жизни граждан, обеспечивает экономический рост и национальный суверенитет».

В общем виде «...цифровая экономика - это использование больших массивов данных в экономической жизни и обычной бытовой жизни с помощью капитализации этих данных, обработки их в режиме онлайн...».

Развитые страны успешно модернизируют экономику, ускоренными темпами развивают инновационные технологии, в которых доминирует искусственный интеллект, автоматизация и цифровые платформы. В 2020 г., по прогнозным данным экспертов, 30\% мировой экономики перейдет к внедрению технологий цифровизации, позволяющих эффективно функционировать государству, бизнесу и обществу.

Аналитический центр Минсельхоза России выделяет ряд проблем цифровизации в АПК:

- низкий уровень охвата digital-техноло- 
гиями с/х производства и сельской местности (уровень цифровизации - менее 10\%), слабое покрытие сетями передачи данных;

- недостаток и неполнота информации о существующих и разрабатываемых цифровых технологиях;

- недостаточное нормативное закрепление правовых основ, обеспечивающих координацию и межведомственное взаимодействие при сборе информации и внедрении цифровых технологий в сельском хозяйстве;

- отсутствие программ, способствующих внедрению (субсидирующих затраты производства) цифровизации, для малых и средних с/х производителей, в том числе личных подсобных хозяйств (ЛПХ);

- отсутствие правовых оснований взаимодействия и сбора информации о деятельности хозяйств населения и связанные с этим ограничения в сфере их поддержки;

- низкая маржинальность (развивающийся сегмент) отрасли - непривлекательность для технологического и инфраструктурного инвестора.

В настоящее время в России правовая база в области цифровой экономики находится в стадии активного формирования. Наиболее важными документами стратегического планирования в данной сфере являются:

- «Стратегия развития информационного общества в Российской Федерации на 2017-2030 годы»;

- Паспорт национальной программы «Цифровая экономика Российской Федерации» (утв. президиумом Совета при Президенте Российской Федерации по стратегическому развитию и национальным проектам протокол от 24 декабря 2018 г. N16);

- Доктрина информационной безопасности Российской Федерации, утвержденная Указом Президента Российской Федерации от 5 декабря 2016 г. № 646;

- Стратегия развития сельскохозяйственного машиностроения на период до 2030 года, утверждена распоряжением правительства РФ от 7 июля 2017 г. № 1455-р;

- Концепция «Индустрии 4.0».

Цифровая экономика - хозяйственная деятельность, в которой ключевым фактором производства являются данные в цифровом виде, обработка больших объемов и использование результатов анализа которых по сравнению с традиционными формами хозяйствования позволяют существенно повысить эффективность различных видов производства, технологий, оборудования, хранения, продажи, доставки товаров и услуг [3].

Американская ассоциация развития цифрового сельского хозяйства (AgGateWay) сформулировало понятие термина «цифровое сельское хозяйство» - это производство агротоваров с применением все более автономных от участия человека производственных и бизнес-процессов, основанных на математических моделях. Источниками первичных данных для этих моделей являются датчики и другие устройства интернета вещей (IоT). Они позволяют агрегировать большие объемы данных и добиваться их высокого качества [4].

Цифровизация сельского хозяйства позволяет не только увеличить объемы производства, но и обеспечить рыночную интеграцию, усовершенствовать механизмы утилизации производственных и пищевых отходов, повысить качество и безопасность пищевых продуктов. По данным Минсельхоза, в настоящее время Россия по уровню цифровизации в сельском хозяйстве занимает 15-е место в мире, только 10\% пашен обрабатываются с применением цифровых технологий. А неиспользование новых методов приводит к потере до 40\% урожая. Интеллектуальные цифровые решения в области сельскохозяйственной отрасли решают проблемы повышения производительности труда и устойчивого развития. Рынок информационнокомпьютерных технологий в сельском хозяйстве составляет порядка 360 млрд.рублей.

Мировыми лидерами по внедрению цифровых технологий являются IT-компании, медиа, финансы и страхование. В реальном производстве и логистике уровень цифровизации значительно ниже, а самый низкий - в сельском хозяйстве (главный сдерживающий фактор особенности ведения агропроизводства).

Основополагающим трендом развития молочной отрасли является цифровизация, которая расширит возможности увеличения объемов производства молока и молочной продукции, а также обеспечивать доходность отрасли за счет индивидуального подхода к животным различного возраста, вида, состояния его здоровья, объема и вида потребляемого корма, окружающей температуры, продуктивности.

Внедрение цифровых технологий в молоч- 
ной отрасли позволит повысить не только эффективность производства и процессов управления фермами, но и кардинально изменить регулирование отрасли. Расширение сфер применения цифровых сервисов позволит проводить аналитику и перейти к управлению отраслью на основе качественного планирования и прогнозирования рисков. Кроме того, цифровизация создает условия для повышения прозрачности рынка для потребителя и положительно повлияет на спрос. Применение технологий цифровой трансформации в молочной промышленности актуально и становится частью конкурентоспособного бизнеса. Поэтому все большее количество молокоперерабатывающих предприятий стремятся к инновациям, связанным с максимальной цифровизацией и автоматизацией бизнес-процессов и производства. Наиболее часто в молочной индустрии используются системы управления деятельностью предприятия.

Проблемой в цифровизации ферм может явиться организация системы сбора первичной информации. Необходимо разграничивать приборное и информационное обеспечение. Приборное, или аппаратное программное обеспечение осуществляет сбор и передачу информации непосредственно с исходных датчиков и сохраняет его в локальной сети. Туда поступают данные от бирок (чипов), установленных на животных, данные о количестве поедаемого корма, количестве выдоенного молока и его составе. Труднее собирать данные о состоянии самого животного. Поэтому одной из задач программы цифровизации является разработка методик и приборов оперативного контроля за состоянием животных. На первом этапе эти данные нужно будет вводить вручную на основании результатов обследования животных.

Информация, передаваемая в сеть, должна содержать более общие данные об объемах производства молока, состоянии стада, данных о системе сбора и хранении молока, физикохимическом составе получаемого молока от каждой дойки. Объём информации при этом должен быть уточнен и формализован, с тем, чтобы представлялся в одинаковых единицах (кг, тоннах и проч.)

Наличие таких данных позволит оптимизировать систему кормления стада, его доения, условий содержания, производить своевременный запуск и ремонт молочного стада. Это возможно при обеспечении фермы соответствующим ком- плексом датчиков, идентифицирующих конкретное животное и его показатели, датчиков расхода кормов (комбикормов), температурновлажностного режима на ферме, учета полученного при дойке молока, санитарного состояния доильного отделения.

Цифровизация молочной фермы позволит обеспечить переход от управления доением к управлению рентабельностью. Цифровая ферма - это совокупность блоков и систем, которые позволяют создать экологическое производство, комфортную среду, автономное энергообеспечение

Согласно исследованиям ФАО ООН переход на цифровые технологии обеспечивает увеличение количества рабочих мест: так, на каждое потерянное вследствие цифровизации рабочее место приходится создание 2,6 новых рабочих мест в результате внедрения информационнокоммуникационных технологий в экономику, облегчения коммерциализации новых идей или стартапов, высвобождения ресурсов для инновационной деятельности.

Важным условием для эффективного использования цифровизации молочной отрасли является выявление узких мест, подлежащих модернизации. Простой сбор информации значительного эффекта не даст, необходима плотная связь с вышестоящей администрацией, потенциальными инвесторами. Это позволит на основании предложений и проектов хозяйств с учетом их деятельности, выбирать наиболее эффективные проекты, готовые к реализации. Наличие развитой информационной системы при детальном анализе информации позволит выявить причины, не позволяющие наращивать объемы производства молока- сырья в России. Оно практически постоянно находится на уровне более $31 \mathrm{Mлн.} \mathrm{тонн.} \mathrm{Увеличение} \mathrm{производства}$ молока позволило бы более полно удовлетворять потребности населения в молочных продуктах, расширить ассортимент продукции, стабилизировать цену на молоко и более рационально использовать его ресурсы.

В сельском хозяйстве активно используется система геопозиционирования, комплексного управления парком техники, точного земледелия. Однако уровень внедрения цифровых технологий в молочной отрасли остается низким. В настоящее время с помощью роботизированных установок производится всего 1\% молочной продукции. Роботизированная карусель - это но- 
вый шаг к цифровизации данной отрасли. Первая в Российской Федерации роботизированная доильная установка карусель GEA DairyProQ запущена в эксплуатацию в Красноярском крае. Уникальность роботизированной «Карусели» в том, что человеческий фактор при ее использовании полностью исключен. Совокупный трудовой процесс осуществляют роботизированные доильные модули, расположенные на каждом доильном месте «карусели» [5].

Среди важных направлений в процессе цифровой трансформации экономики являются роботизация (в том числе, использование дронов) и работа с «большими данными», в том числе, развитие систем искусственного интеллекта. Актуальность опережающего развития этих направлений цифровизации для АПК России обусловлена тем, что это позволит не только резко повысить эффективность сельскохозяйственного производства, но и сократить количество работников, необходимых для производства сельскохозяйственной продукции.

Эффективным инструментом в достижении нового уровня цифровизации является «Интернет вещей» (далее IоT), который представляет собой сеть связанных через интернет объектов, способных собирать данные и обмениваться данными, поступающими со встроенных сервисов. Области применения технологии ІоТ в молочной промышленности:

- «умное стадо»;

- «умные фермы» - это полностью автоном- ный, роботизированный, сельскохозяйственный объект, предназначенный для разведения сельскохозяйственных видов/пород животных (мясные, молочные и др.) в автоматическом режиме, не требующий участия человека (оператора, животновода, ветеринара и др.). Такая ферма самостоятельно производит анализ экономической целесообразности производства, потребительской активности, уровня общего здоровья населения региона и других экономических показателей, используя необходимые цифровые технологии (искусственный интеллект, интернет вещей, большие данные, нейронные сети и др.), на основании такого анализа, ферма принимает решение какие виды/породы сельскохозяйственного животного (с заданными качественными и количественными показатели) необходимо разводить;

- формирование баз данных по комплексу факторов, влияющих на продуктивность и продолжительность продуктивного периода молочного скота;

- применение позволяет снизить уровень заболеваемости животных маститом на 70\%; повысить качество молочной продукции более чем на 40\%; рентабельность продукции с «Умных» ферм более $40 \%$;

- управление сырьем;

- управление транспортом. Мониторинг транспорта с помощью ГЛОНАCC, GPS и датчиков позволяет снизить расход горючего, а также оптимизировать маршруты и загрузку персонала;

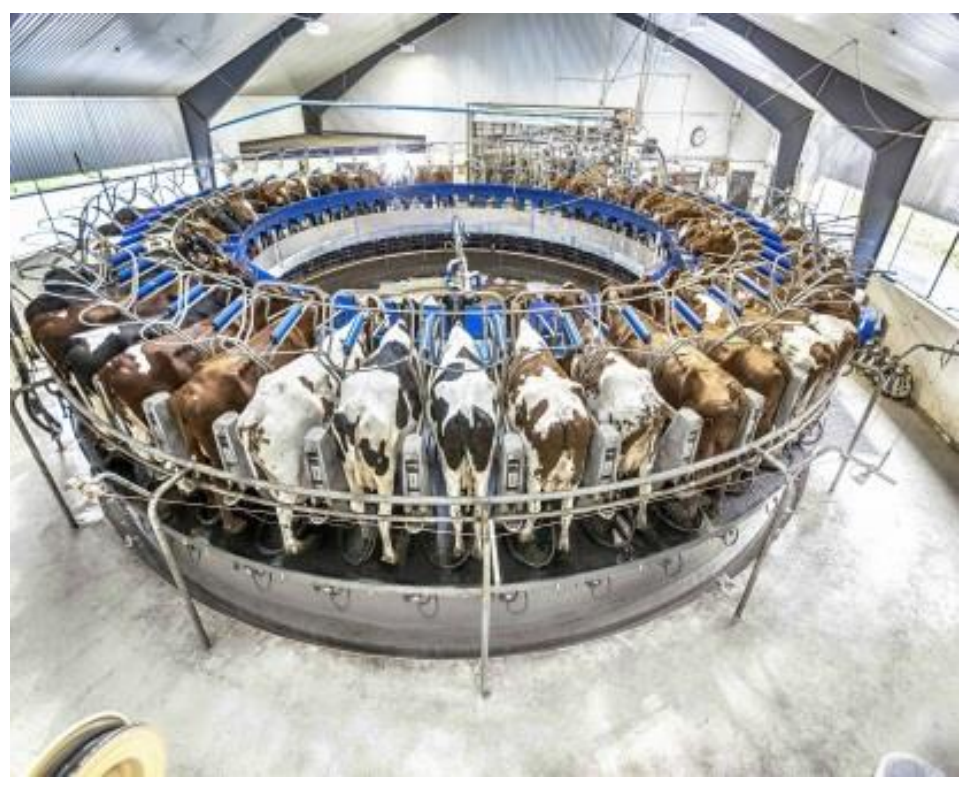

Puc. 1. Роботизированная доильная установка карусель GEA DairyProQ 
- управление хранением. Для сохранности сырья в процессе его сбора и перемещения используются соответствующие датчики, позволяющие полностью отслеживать как местонахождение, так и вес перемещаемого сырья. Специально заданные алгоритмы в режиме реального времени осуществляют мониторинг состояния продукции при хранении (температурный режим хранилищ, уровень влажности, содержание углекислого газа) и помогают принять правильное решение.

- «большие данные».

Таким образом, «умное молочное производство» позволяет максимально автоматизировать производственную деятельность, повысить качество продукции.

По предварительной оценке, общий минимальный экономический эффект от внедрения технологии ІоТ в сельском хозяйстве за период до 2025 г. может составить около 469 млрд. руб. за счет оптимизации затрат на персонал; сокращения потерь урожая (зерна); сокращения потерь горюче-смазочных материалов (ГСМ) [1].

В России модернизация предприятий молочной отрасли в последние годы ускорилась. Это произошло благодаря введенным ограничениям на импорт, наращиванию производства молока отечественными производителями, а также системным мерам государственной поддержки и борьбе с фальсификацией. На современных предприятиях работают кормовые и доильные роботы, системы очистки комплексов, управления стадом, учета количества животных и состояния здоровья каждого из них. Модернизация производства позволяет увеличить молочную продуктивность коров, уменьшить затраты на обслуживание фермы, повысить качество продукции и снизить ее себестоимость. В 2018 году компания «ОСП агро» ввела в эксплуатацию животноводческий комплекс на 2 тыс. голов. Комплекс площадью около 22 тыс. кв.м оборудован системой кросс-вентиляции, а автоматическая система управления светом регулирует продолжительность светового дня для разных групп животных в зависимости от стадии лактации. Таким образом, производительность труда на ферме на 70\% выше, чем на аналогичных по размеру предприятиях, в которых используются традиционные технологии,

В 2019 году «ОСП агро» завершило строительство молочно-товарной фермы на 1199 коров. Новая ферма оснащена доильным залом
«Карусель» - с внутренним обслуживанием на 40 доильных мест с оптимальной позицией животных под углом 40 градусов к дояру для лучшего обзора и доступа. На дойку при таком подходе требуется около 11 минут - вдвое меньше, чем обычно. Комплекс по выращиванию молодняка включает в себя автоматическую систему выпаивания телят. Коров на ферме чипируют, отслеживая данные о здоровье и продуктивности.

Таким образом, в молочном производстве распространяются роботы и искусственный интеллект. Электронные (цифровые) инструменты контроля качества приходят в систему производства и сбыта молочной продукции.

Электронные технологии внедряются в систему регулирования молочной индустрии. Правительство Московской области в апреле 2018 года запустило «Электронный магазин», в котором поставщики размещают предложения о продаже товара, информацию о выполнении работы или оказании услуг. За время работы портала совершено свыше 290 тыс. закупок на сумму более 16 млрд.руб. В «Электронном магазине» зарегистрированы 85 тыс. поставщиков, а также им пользуются 7,5 тыс. бюджетных учреждений.

С 1 июня 2020 года молочную продукцию затронет процесс маркировки. С 01 июля 2018 года в России функционирует система электронной ветеринарной сертификации «Меркурий», которая обеспечивает контроль от производства сырья до продажи готовой продукции. В настоящее время охвачена только часть планируемой цепочки «от поля до прилавка» - сырье. В наиболее полном масштабе данная система будет функционировать, после того как она распространится и на готовую продукцию. Электронная ветеринарная сертификация - это шаг в развитии контроля и защиты российских аграриев, и выведение готовой молочной продукции из-под ее действия замедляет это развитие. По просьбе Министерства промышленности и торговли РФ петербургские ученые добавили к данной системе технологию слияния данных DataFusion и систему QR-кодов, после чего объединили эти массивы на базе технологии блокчейн. На упаковку товара будет наноситься код DataMatrix, который покупатели смогут считывать при помощи смартфона. Так они получат сведения о происхождении молока и дате надоя, подробностях транспортировки сырья до завода, произведенных анализах, дате выпуска конкретной упаковки товара, добавлении дополнительных 
ингредиентов. Разработчики полагают, что технология позволит снизить незаконный оборот молочной продукции.

В 2018 году производитель и поставщик кормов и кормовых добавок «Мустанг Технологии кормления» вместе с компанией «Алан-ИТ» разработали систему искусственного интеллекта для молочных ферм на платформе Microsoft. Программа ведет онлайн-мониторинг производства молока, контроль стада (воспроизводства, болезней и выбытия), составляет аналитические отчеты и прогнозы. Кроме того, система вычисляет затраты на корм, выявляет малопродуктивных коров, оценивает себестоимость, рентабельность производства, а также выстраивает систему мотивации персонала. По данным разработчиков, надои молока на предприятиях, где используется эта система, выросли в среднем на 9\%. Все процессы на предприятии в режиме онлайн можно контролировать с помощью смартфона, планшета или компьютера. Производство молока - высокотехнологичный бизнес, который позволяет генерировать устойчивый доход. Именно для работы с большими массивами данных предназначена система искусственного интеллекта.

Активно используются и автоматизированные системы. Так, система LelyVector, разработанная компанией Lely (Нидерланды), состоит из робота для смешивания и подачи корма животным и кормовой кухни, в которой хранится корм. Роботизированная система доения LelyAstronaut A5 обеспечивает бесперебойное доение в режиме 24/7 и формирует отчеты по доению, качеству молока и здоровью животных в программе управления стадом Lely $\mathrm{T} 4{ }^{\circ} \mathrm{C}$, a также составляет рацион для автоматизированной системы кормления LelyVector. Программа Lely $\mathrm{T} 4{ }^{\circ} \mathrm{C}$ помогает легко контролировать доение и кормление.

Компьютерная система управления процессом доения «Стимул»- современная, высокотехнологичная, наукоемкая, инновационная разработка. «Стимул» отличается улучшенными свойствами функциональной диагностики, отладки, живучести и надежности, снижающими влияние человеческого фактора в нештатных ситуациях в системе «человек - доильный аппарат - животное». Освоение ее промышленного производства позволит решать проблему импортозамещения зарубежного автоматизированного доильного оборудования.
В настоящее время широкое распространение получила созданная «Плинор» компьютерная система племенного учета (АСУ ПУ «Селекс»), основными функциями которой являются [6]:

- автоматизация первичного учета;

- оперативное управление селекционноплеменной работой;

- бонитировка и ее анализ;

- учет и анализ качественных показателей молока по каждой корове;

- прогнозирование производства продукции (модуль продуктивности)

- работа с молодняком;

- обмен данными с компьютерной системой доения «Стимул»;

- экономический анализ (модуль экономики);

- модуль «подготовка данных для передачи данных в бухгалтерские программы».

Интегрированная система «Стимул» - «Селекс» является первым отечественным инструментом для ведения автоматизированной широкомасштабной селекции животных в хозяйствах Российской Федерации. Концепция дальнейшего развития интегрированной компьютерной системы КСУ «СТИМУЛ-СЕЛЕКС», как базовой платформы цифровизации в молочном животноводства, в соответствии с технологиями четвертой промышленной революции «Индустрия 4.0», которая определяется производственной средой, в которой основные компоненты производства подключаются к Интернету.

Наличие информации о состоянии пастбищ и участков заготовки кормов позволит объективно планировать деятельность по обеспечению молочного стада кормами. Так, например, в республике Казахстан успешно реализованы цифровые технологии для точного картирования сырьевых зон молочных заводов и нанесения информации требований технического регламента для каждого поставщика молока. Используя цифровые технологии и космоснимки можно работать с кормовой базой, которая составляет порядка половины себестоимости молока.

Также, в Казахстане внедрено мобильное приложение и сопутствующая методика под названием «Collect mobile», которое разработано в целях сбора данных на местах и их анализа для составления отчетности. Данная цифровая технология помогает переработчику четко и поэтапно решать основные проблемы с качеством сырья. Переработчик самостоятельно решает 
вопрос, какой параметр необходимо отследить. $\mathrm{K}$ примеру, если необходимо определить какая санитария, соматика или антибиотик в молокоприемном пункте, то выбираются нужный перечень вопросов и данные собираются по необходимости.

Развитие цифровых технологий позволит оценить не только общее состояние участков заготовки кормов, но и определить наличие на нем зоны с наличием нежелательных и вредных веществ (пестицидов, хлорорганики и других).

Анализ информации работы молоковозов занимает значительный промежуток времени. Используя системы координат GPS, который встроен на планшет, контролируется путь и время перемещения молоковоза, частота сбора молока, а также производится расчет амортизации и другие необходимые показатели. Это сокращает время работы сотрудника отдела закупки молока. Также это позволяет фильтровать тех поставщиков, которые входят в нужную сырьевую зону и у которых имеется доильный аппарат, у кого хорошее состояние доильного стакана, доильного шланга, низкие показатели бактериальной обсемененности, молочную продуктивность и количество голов. На основании собранных данных можно принять решение по установке молокоприемного пункта. Таким образом, с помощью приложения, установленного на смартфоне или на планшете, можно провести опрос среди поставщиков и узнать их основные слабые и болевые места. Поскольку главная цель - итоговая оценка поставщиков. Для этого разработана методика (5 балльной система) для оценки поставщика, для того, чтобы иметь адекватную оценку, позволяющую установить, насколько эффективно работает данная животноводческая база, и как можно решить проблемы.

Цифровые технологии и космоснимки служат для мониторинга эффективности инвестиций. В этом деле используется сервис Google Earth. Используя средства GPS можно проанализировать, насколько эффективно используются ресурсы на ферме.

ФАО выпустила также для поставщиков молока Казахстана первый образовательный материал в виде мультфильма «Смарт сүт». Также имеются продукты такие как «калькулятор потери», «как правильно составлять баланс молочного скота».

В Восточной Европе Сербия создавала ар- битражную лабораторию и зафиксировала рост качества молока при укрупнении хозяйств и их соответствии стандарту. Подобный анализ проводился и по предприятиям России [6].

В Хорватии в настоящее время находится по качеству молока на хорошем уровне. Их опыт наиболее успешный в Восточной Европе и все участники рынка могут видеть какая ситуация в стране по параметрам и эта информация служит для определения государственной политики [7].

Стратегически ожидается, что в соответствии с планами по развитию технологий IоT в агропромышленном комплексе, доля предприятий, использующих решения IоT, к 2021 году может составить 50\% [7].

Неотъемлемой частью повышения активности предприятий АПК в процессах внедрения цифровых технологий в производство является широкое распространение информации о новейших научных достижениях, в том числе, IT-технологиях. Этому способствует научноинформационное обеспечение в сфере сельского хозяйства, осуществляемое ФГБНУ «Росинформагротех» [1]. Преодолению имеющихся барьеров на пути внедрения цифровых технологий в аграрный сектор экономики России, ускорению перевода отрасли на новый технологический уровень развития будет способствовать совместная работа разработчиков и интеграторов ИТ-решений в сельском хозяйстве, инвесторов, представителей экспертного сообщества и органов власти.

Таким образом, внедрение цифровизации может оказать большую помощь в решении целого ряда вопросов по улучшению качества молочной продукции, объемов производства и заготовки молока для промышленной переработки, повышению эффективности производства и переработки молока. При этом следует отметить, что эффективное применение цифровых технологий может дать положительный результат при наличии специализированных программ обработки информации, моделирования ситуаций на основе математических моделей деятельности агропромышленных комплексов и отдельных конкретных объектов и предприятий. Одной из основных задач при этом следует отметить подготовку специалистов, владеющих как программными, так и аппаратными средствами цифровизации. 


\section{Библиографический список}

1. Федоров А.Д. Цифровизация сельского хозяйства - необходимое условие повышения его конкурентоспособности / А.Д. Федоров// Журнал «Нивы России». - 2018. - № 5 (160). - С. 36-39.

2. Юрина Н.Н. Направления цифровизации сельского хозяйства России / Н.Н. Юрина// Вестник института экономики и управления НовГУ. - 2018. - № 2(27). - С. 92-97.

3. Указ Президента РФ от 09.05.2017 N203 «О Стратегии развития информационного общества в Российской Федерации на 2017-2030 годы».

4. agroinvestor.ru>column/nikolay-lychev/30711...u-nas...

5. gea.com>russia/Milking-Carousel-Dairy-ProQ.jsp

6. Седов А.М. Цифровая трансформация управления в молочном животноводстве на базовой платформе интегрированных компьютерных систем «СТИМУЛ» и «СЕЛЕКС» / А.А. Седов // Журнал «Инновации в сельском хозяйстве».-2018.- № 1 (26). - С. 357-367.

7. Электронный ресурс: http://www.fao.org/about/meetings/ru/).

8. Стабильность работы молокоперерабатывающих предприятий // Абдулрагимов И.А., Сурай Н.М., Логинов В.А., Майоров А.А / Вопросы экономики и права. - 2018. - № 5 (119). - С. $92-98$ 